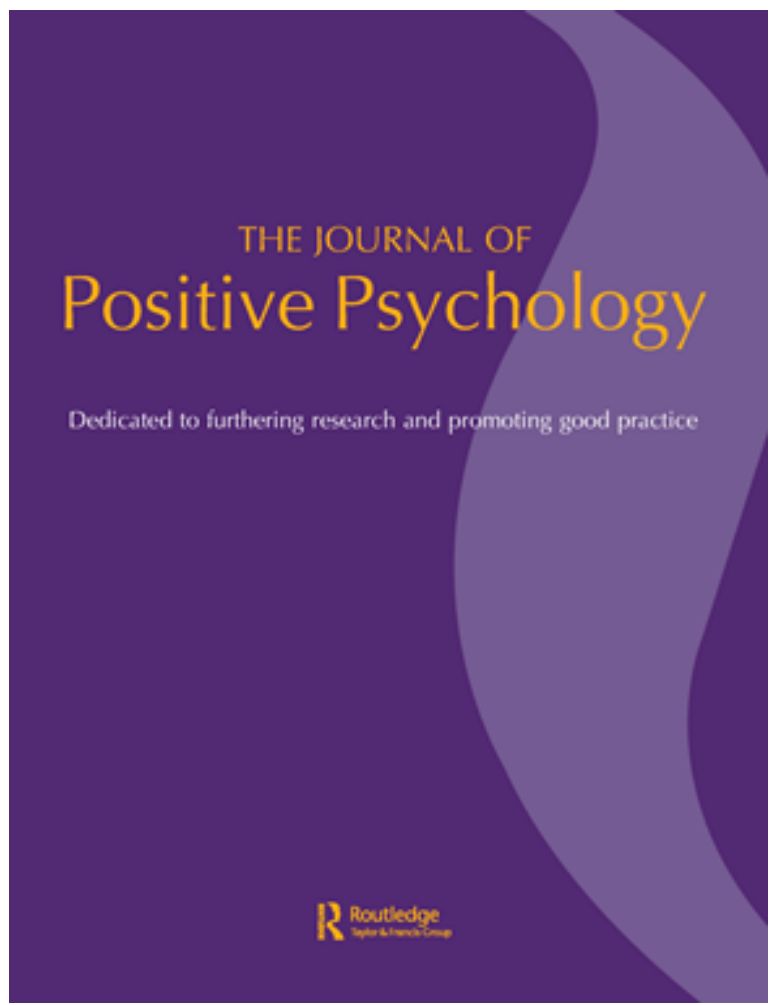

\title{
Examining within-person relationships between state assessments of affect and eudaimonic well-being using multi-level structural equation modeling
}

\begin{tabular}{|r|l|}
\hline Journal: & The Journal of Positive Psychology \\
\hline Manuscript ID & RPOS-2020-0365 \\
\hline Manuscript Type: & Original Paper \\
\hline Author: & $21-J u l-2020$ \\
\hline Complete List of Authors: & $\begin{array}{l}\text { Jayawickreme, Eranda; Wake Forest University, Psychology } \\
\text { Tsukayama, Eli; University of Hawai'i West O'ahu } \\
\text { Blackie, Laurie; University of Nottingham, Psychology } \\
\text { Weiss, Brandon; University of Georgia }\end{array}$ \\
\hline Keywords: & meaning, purpose, affect, well-being \\
\hline Keywords (author supplied): & individual differences, within-person differences \\
\hline &
\end{tabular}

\section{SCHOLARONE" \\ Manuscripts}


STATE AFFECT AND EUDAIMONIA

\title{
Examining within-person relationships between state assessments of affect and eudaimonic well-being using multi-level structural equation modeling
}

\author{
Eranda Jayawickreme \\ Wake Forest University \\ Eli Tsukayama \\ University of Hawaii-West Oahu \\ Laura E.R. Blackie \\ University of Nottingham \\ Brandon Weiss \\ University of Georgia
}
Keywords: meaning, purpose, affect, authenticity, core self-evaluations, gratitude, well-being, within-person differences

\begin{abstract}
Jayawickreme and Tsukayama are joint lead authors on this article. This research was made possible by a grant from the John Templeton Foundation (24322; PI Eranda Jayawickreme). The contents and the opinions expressed in this article are those of the authors and do not represent the views of the John Templeton Foundation. Correspondence concerning this article should be addressed to Eranda Jayawickreme, Department of Psychology \& Program for Leadership and Character, Wake Forest University, P.O. Box 7778, Winston-Salem, NC 27109. Email: jayawide@wfu.edu, ORCID ID: https://orcid.org/0000-0001-6544-7004
\end{abstract}




\section{STATE AFFECT AND EUDAIMONIA}

\section{Compliance with Ethical Standards}

Ethical approval: All procedures performed in studies involving human participants were in accordance with the ethical standards of the institutional research committee and with the American Psychological Association's ethical standards. The study was reviewed and approved by the Wake Forest IRB prior to data collection (IRB \# IRB00021398). No study involved research on animals.

Conflict of interest: The authors have no known conflicts of interest to disclose.

Availability of data and materials: All data and materials are available from the first author upon request.

Code availability: All code utilized in the analyses are available from the first author upon request.

Funding: This study was funded by a grant from the John Templeton Foundation (grant ID: 24322).

Informed consent: Informed consent was obtained from all individual participants included in the study.

Authors' contributions: EJ, ET and LB conceived the study; EJ, LB and BW developed materials and collected data; ET ran the analyses; EJ and ET drafted the paper; all authors provided feedback and edits on the final document. 
STATE AFFECT AND EUDAIMONIA

\begin{abstract}
Prior research has highlighted the possibility that current affect may be interchangeable with state assessments of other dimensions of subjective well-being. In the present study, we conducted a systematic replication and extension by examining the relationship between state assessments of affect and eudaimonic well-being (meaning, core self-evaluation, authenticity, and gratitude) in a 14-day diary assessment ( $N=207$ with 2,147 assessments). We utilized multi-level structural equation modeling (ML-SEM) with affect as a time-varying covariate and found that the impact of affect for these outcomes was less consequential than for assessments of state satisfaction, and that the impact of positive affect on these dimensions was stronger than that of negative affect.
\end{abstract}

Keywords: meaning, purpose, affect, individual differences, well-being, within-person differences 


\title{
STATE AFFECT AND EUDAIMONIA
}

\section{Examining within-person relationships between state assessments of affect and eudaimonic well-being using multi-level structural equation modeling}

Prior research has highlighted the possibility that current affect may be interchangeable with state assessments of life satisfaction at the within-person level (Jayawickreme, Tsukayama, and Kashdan, 2017a). While this finding points to the potential disutility of measuring distinct subjective well-being (SWB) states, it is unknown whether this extends to other dimensions of well-being. Here we present the results of a systematic replication and extension of Jayawickreme and colleagues (2017a), which employed a multi-level structural equation model examination of the within-person relationship between state assessments of affect and life satisfaction. This study found that measures of state affect and satisfaction were redundant in the sense that within-person changes in state affect perfectly explained within-person changes in state satisfaction. The goal of the present investigation was to ascertain whether state assessments of key dimensions of eudaimonic well-being (EWB) provide distinct information about individuals' well-being over and above their current affect.

\author{
Assessing well-being \\ Psychologists have assessed well-being in many forms over the last half-century \\ (Jayawickreme, Forgeard, \& Seligman, 2012). One consistent distinction in this literature is that \\ between the affective and cognitive components of SWB (Diener, 1984) on the one hand, and \\ EWB on the other. While a variety of definitions of EWB exist in the literature (Jayawickreme \& \\ Dahill-Brown, 2016), a unifying theme is that EWB distinctively reflects positive functioning \\ that emanates from the possession of key dimensions of human thriving (e.g., the psychological \\ well-being [PWB] perspective; Ryff, 1989). These dimensions include the ability to choose and
}




\section{STATE AFFECT AND EUDAIMONIA}

create environments that fit one's personality, having positive interpersonal relationships, holding positive self-evaluations of one's past and present self (i.e., self-acceptance), developing and growing as a person, and possessing self-determination, independence, self-regulation of behavior, meaning and purpose in life, and authenticity (Ryff, 1989; Waterman, 1993; 2008; Jayawickreme \& Dahill-Brown, 2016).

These forms of well-being can be assessed with both trait and state (experiential) measures. Global or trait well-being measures are posited to assess individuals' beliefs about the overall well-being of their lives, whereas state well-being measures aim to assess short-term or momentary reports of well-being in the context of lived experiences (Hudson, Lucas \& Donnellan, 2017). Notably, previous research has indicated that reports of state well-being are influenced by appraisals of global life circumstances (Luhmann, Hawkley, Eid, and Cacioppo, 2012).

\section{Examining the role of affect in well-being judgements}

A major contemporary issue relevant to the valid measurement of state well-being is whether individuals, when reporting on state well-being, rely on information unique to wellbeing (involving global evaluations) or instead rely merely on their current affect (see Jayawickreme et al., 2017a and Jayawickreme, Tsukayama, \& Kashdan, 2017b for a more indepth discussion). In other words, if someone reports their current level of well-being, to what extent would they use their current level of affect to guide their answer? We define this "effect of affect" on well-being as the proportion of total variance in well-being explained by changes in affect over time. For life satisfaction, the effect using a trait measure assessed weekly was relatively inconsequential as there was relatively little within-person variance in trait life 


\section{STATE AFFECT AND EUDAIMONIA}

satisfaction $(.12 ; 9 \%$ of the total variance) from week to week over a five week period (Jayawickreme et al., 2017b). In contrast, the "effect of affect" was more consequential for daily state measures of life satisfaction due to greater within-person variance over a two-to-three week period (.87; $49 \%$ of the total variance); current affect accounted for $100 \%$ of the within-person variance in state satisfaction assessments (Jayawickreme et al, 2017a).

These findings suggest that there is an "effect of affect" that is specific to daily or state assessments of life satisfaction and raise the possibility that current affect may have a substantial impact on state assessments of other dimensions of well-being. This is because whereas past research has argued for a clear distinction between SWB and PWB on conceptual grounds (e.g. Ryff, 1989), existing research has found support for a link between affect and state meaning (e.g. King, Hick, Krull, \& Del Gaiso, 2006) as well as for between mood and state authenticity (Lenton, Slabu, Sedikides, \& Power, 2013). More generally, some researchers have questioned the extent to which SWB and EWB are in fact empirically distinguishable (e.g., Disabato et al., 2016; Kashdan, Biswas-Diener, \& King, 2008).

These considerations lead to the following question: does current affect explain the within-person variability in state assessments of EWB (such that measuring state EWB would be interchangeable with measuring current affect), or does state EWB provide unique information on state well-being over and above current affect? We answer this question here through a systematic replication and extension of Jayawickreme and colleagues (2017a) where we examined the impact of affect on state assessments of four distinct dimensions of EWB: meaning, core self-evaluation (the fundamental appraisals individuals make about their selfworth and capabilities), authenticity, and gratitude. In doing so, we examine whether current affect impacts state assessments of EWB to the same extent as it impacts state satisfaction. 


\section{STATE AFFECT AND EUDAIMONIA}

\section{Using multi-level structural equation models (ML-SEM) to assess within-person relationships}

We note that we use multi-level structural equation models (ML-SEM) that can distinguish between "state" (i.e., deviations from an individual's average across time) and "trait" (i.e., stable between-individual differences) variance for these analyses. Baumert and colleagues (2017) have highlighted the importance of integrating personality process, structure, and development, and answering such questions necessitate the examination of dynamics of trait change, intraindividual variability of states and traits, and the interrelations between states and traits (Kandler, 2017) at both the fine-grained and long-term level (Finnigan \& Vazire, 2017).

To assess personality at the within-person state level, it is important to use appropriate measures and statistical models (Brose, Schmiedek, Gerstorf, \& Voelkle, 2020). Prior research has mostly examined the affect-well-being relationships at the between-person level (e.g., the proportion of overlapping variance between affect and life satisfaction; Diener, Fujita, Tay, \& Biswas-Diener, 2012; Kuppens, Realo, \& Diener, 2008; Suh, Diener, Oishi, \& Triandis, 1998). One limitation of this work is that once a relationship among two variables is identified at the global (between-person) level, it is often inferred that the relationship holds true at the momentary (within-person) level (i.e., the ecological fallacy). As discussed by Jayawickreme and colleagues (2017a; 2017b), within-person approaches may reveal different answers than between-person approaches, since the causes for why variables may vary across people may be different from why they vary within a person across situations. Many key questions related to the impact of states on traits are fundamentally within-person questions, and the direction and 


\section{STATE AFFECT AND EUDAIMONIA}

magnitude of any identified impact will vary depending on the level of analysis (Molenaar \& Campbell, 2009).

Using multi-level structural equation modeling (ML-SEM) to address questions regarding (1) partitioning total variance into between-person "trait" (i.e., stable between-individual differences) and within-person "state" (i.e., deviations from an individual's average across time) components, and (2) estimating within-person relationships between state variables holds unique advantages. The multilevel aspect of the ML-SEM allows the simultaneous analysis and comparison of the within- and between-person relationships among variables, whereas the structural equation modeling aspect enables the separation of error variance from reliable latent constructs. Without this technique, error variance would be confounded with within-person variance. Moreover, the critical question of whether reports of well-being largely assess current affect is fundamentally a within-person question. In other words, do changes in affect impact changes in well-being for a particular person? For example, if an individual's current positive affect increases, will her EWB rating also increase?

The ML-SEM approach employed here is also different from more classical state-trait models (e.g., Eid \& Diener, 2004). State-trait models use a residual-based approach that addresses the ecological fallacy discussed above by removing overall between-person variance from the occasion-specific effects. In other words, the occasion-specific variables are residuals (or deviation scores) that have been adjusted / control for the trait (i.e., an individual's average over time), and these models examine effects across individuals within occasions (e.g., does a person with a relatively large occasion-specific residual of well-being also have a relatively large occasion-specific residual of affect relative to other individuals?). However, this approach is conceptually complicated and relatively difficult to interpret/comprehend. Our approach is 


\section{STATE AFFECT AND EUDAIMONIA}

conceptually more straightforward/direct (where the impact of affect is basically the withinperson relationship between affect and EWB).

\section{The Present Study}

In the present study, we evaluated state assessments of four dimensions of EWB: meaning, core self-evaluation, authenticity, and positive relationships.

Meaning. Meaning has been seen in the psychological literature as distinct from happiness (Baumeister, 1991; Hicks \& King, 2007; Ryff \& Keyes, 1995; c.f. Disabato et al., 2016). Typically, whereas measures of subjective well-being are seen as contributing to hedonia, meaning is seen as a central dimension of eudaimonia (i.e., well-being derived not from pursuing momentary desires but rather experiences that promote growth and wellness) (Ryan \& Deci, 2001; Dahill-Brown \& Jayawickreme, 2016). Of note, the present work replicates and extends previous examinations of relations between affect and daily meaning (e.g. King et al., 2006) while employing a novel statistical approach. Specifically, our models produce separate estimates of both the between- and the within-person impact of affect on meaning, whereas prior work (e.g., Study 2 in King et al., 2006) did not distinguish between them, which produces a confounded amalgam of the two effects. Furthermore, our models use latent variables to adjust for measurement error.

Core self-evaluation. Core self-evaluations refer to the fundamental appraisals individuals make about their self-worth and capabilities (Bono \& Judge, 2003). The constructs of self-esteem, neuroticism, locus of control, and generalized self-efficacy have typically made up the key dimensions of this construct (Judge et al., 2002). Notably, they capture key features of meaningful goal-directedness characteristic of EWB theories (specifically, holding positive self- 


\section{STATE AFFECT AND EUDAIMONIA}

evaluations of oneself, and possessing qualities such as self-determination, independence, selfregulation of behavior; Ryff, 1989).

Authenticity. Authenticity, or the sense that one generally acts in a manner congruent with one's true self, has been seen by some theories as a central dimension of EWB (Sheldon \& Kasser, 2001; Waterman, 1993; 2013). State authenticity has been defined as the sense that one is currently in alignment with one's true or genuine self (Sedikides, Slabu, Lenton, \& Thomaes, 2017). It is frequently reported in daily life (Lenton et al., 2013) and is associated in increased subjective vitality (Thomaes et al., 2017) and meaning (Schlegel et al., 2009). Moreover, experimental work has suggested that people use current mood information in evaluating their state authenticity (Lenton et al., 2013).

Positive Relationships: Ryff (1989) identified positive relationships as a key dimension of EWB. Ryan and Deci (2001) have similarly identified relatedness - the importance of feeling a close connection to and being cared for by others - as one of three psychological needs that contribute to a flourishing life. The importance of positive relationships has been shown to be valued across cultures (Sheldon, Elliot, Kim \& Kasser, 2001) and further relates to measures of life satisfaction (Reis, Sheldon, Gable, Roscoe, \& Ryan, 2000; Sheldon, Ryan, \& Reis, 1996).

\section{Materials and Methods}

Participants. 207 participants were recruited from Amazon.com’s Mechanical Turk online recruitment platform. Due to a coding error, demographic information for three of these participants were not recorded. The mean age of the 204 participants for which we obtained demographic information was $33.72(S D=10.78)$ with 109 identifying as men and 95 as women. In terms of self-reported racial background, 167 reported being White, 15 were Black, 17 were Asian, and 4 were from other racial backgrounds. Participants completed assessments of well- 


\section{STATE AFFECT AND EUDAIMONIA}

being at the end of each evening for a period of 14 consecutive days (see Table 1 for the list of item). They received a link to the survey (which was hosted on the Qualtrics survey platform) each evening via email.

\section{Measures}

State meaning. State meaning was assessed with four items adapted from the Meaning in Life questionnaire (Steger, Frazier, Oishi, \& Kaler, 2006). The estimated reliability was .98 at the between-person level and .94 at the within-person level. ${ }^{1}$

State affect. Participants rated one item measuring positive affect ("Today, I felt happy"), and one item measuring negative affect ("Today, I felt sad), following Kashdan and Steger (2006). These items were rated on a seven-point scale ranging from "Did not feel this way at all" to "Felt this way very strongly."

State core self-evaluation. State core self-evaluation was assessed using 10 items adapted from the CORE Inventory (Judge et al., 2002). We did not include two emotion-related items that might artificially inflate the relationship of core self-evaluations with our emotion predictors: "I felt depressed today" and "Today, I felt things were pretty bleak and hopeless." The estimated reliability was .99 at the between-person level and .98 at the within-person level.

State authenticity. State authenticity was assessed using three items adapted from Heppner and colleagues (2008). The estimated reliability was .93 at the between-person level and .89 at the within-person level.

Positive Relationships. State positive relationships was assessed with two items adapted from the Positive Relationships with Others subscale of the Psychological Well-Being

\footnotetext{
${ }^{1}$ To estimate multilevel reliability (see Geldhof, Preacher, \& Zyphur, 2014), we ran multilevel confirmatory factor models and computed omega using the following formula: $\omega=\left(\sum \lambda\right)^{2} /\left[\left(\sum \lambda\right)^{2}+\sum \psi^{2}\right]$.
} 


\section{STATE AFFECT AND EUDAIMONIA}

Questionnaire (Ryff \& Keyes, 1995). The estimated reliability of these items was .85 at the between-person level and .80 at the within-person level.

\section{Procedures and analytic approach}

We used multilevel structural question modeling (ML-SEM) with affect as a timevarying covariate in Mplus 7 (Muthén \& Muthén, 2012). The multilevel aspect of our analyses allowed us to analyze and compare the within- and between-person relationships between affect and eudaimonic well-being simultaneously, whereas the structural equation modeling feature of our models enabled us to separate error variance from reliable latent constructs. Without this technique, error variance would be confounded with within-person variance. To scale the latent constructs, we used the effects-coding method of scaling (Little, Slegers, \& Card, 2006). This method allows the latent construct to remain in the same scale as the indicator variables. As a measure of effect-size, we used $r_{\text {effect }}=\sqrt{ }\left[t^{2} /\left(t^{2}+d f\right)\right]$ (see Duckworth, Tsukayama, \& May 2010; Rosenthal \& Rosnow, 1991, p. 441). We conducted a series of ML-SEM models. For each wellbeing outcome, Model 0 was an unconditional model with no predictors to estimate the amount of variance in well-being at each level (between- and within-person) and to serve as a baseline model against which to compare subsequent models including predictors. We added positive affect (Model 1) and negative affect (Model 2) individually and simultaneously (Model 3) as predictors of well-being at both the within-person and between-person levels. In Models 1-3, the within-person effects/slopes were allowed to vary across individuals (i.e., treated as random).

\section{Results}

Meaning. In Model 0 (no predictors), the variance estimates for daily meaning were 0.57 at the between-person level and 0.26 at the within-person level (see Table 2). The intraclass 


\section{STATE AFFECT AND EUDAIMONIA}

correlation (ICC) was .69 indicating that more than half of the variance was between-person (69\%) vs. within-person (31\%).

In Model 1 (positive affect), the between-person impact of positive affect was .82 (95\% CI $\left.[.74, .90], r_{\text {effect }}=.81, p<.001\right)$ and explained $66 \%$ of the between-person variance. At the within-person level, the impact of positive affect was .53 (95\% CI $[.48, .57], r_{\text {effect }}=.84, p$ $<.001$ ) and explained $57 \%$ of the within-person variance in daily meaning.

In Model 2 (negative affect), the between-person impact of negative affect was -.48 (95\% CI $\left.[-.58,-.37], r_{\text {effect }}=-.53, p<.001\right)$ and explained $32 \%$ of the between-person variance. At the within-person level, the impact of negative affect was -.31 (95\% CI $[-.36,-.26], r_{\text {effect }}=-.67, p$ $<.001$ ) and explained $35 \%$ of the within-person variance in daily meaning.

In Model 3 (both positive and negative affect), at the between-person level, the impact of positive affect was $.80\left(95 \% \mathrm{CI}[.67, .92], r_{\text {effect }}=.65, p<.001\right)$ and the impact of negative affect was $-.03\left(95 \%\right.$ CI $\left.[-.13, .07], r_{\text {effect }}=-.04, p=.57\right)$, together explaining $66 \%$ of the betweenperson variance in daily meaning. At the within-person level, the impact of positive affect was $.46\left(95 \% \mathrm{CI}[.41, .51], r_{\mathrm{effect}}=.82, p<.001\right)$ and the impact of negative affect was $-.11(95 \%$ CI $\left.[-.14,-.08], r_{\text {effect }}=-.41, p<.001\right)$ together explaining $60 \%$ of the within-person variance in daily meaning.

Using a state/daily measure of meaning, there was substantial within-person variance, about $31 \%$. In addition, there was a substantial impact of affect for the state meaning measure $\left(R^{2}=.60\right)$.

Core Self-Evaluations. In Model 0 (no predictors), the variance estimates for daily selfevaluations were 0.37 at the between-person level and 0.30 at the within-person level (see Table 


\section{STATE AFFECT AND EUDAIMONIA}

3). The intraclass correlation (ICC) was .56 indicating that more than half of the variance was between-person (56\%) vs. within-person (44\%).

In Model 1 (positive affect), the between-person impact of positive affect was .61 (95\% CI $\left.[.55, .67], r_{\text {effect }}=.83, p<.001\right)$ and explained $86 \%$ of the between-person variance. At the within-person level, the impact of positive affect was $.45\left(95 \% \mathrm{CI}[.41, .50], r_{\mathrm{effect}}=.82, p\right.$ $<.001)$ and explained $66 \%$ of the within-person variance in daily self-evaluation.

In Model 2 (negative affect), the between-person impact of negative affect was -.42 (95\% CI $\left.[-.49,-.36], r_{\text {effect }}=-.65, p<.001\right)$ and explained $69 \%$ of the between-person variance. At the within-person level, the impact of negative affect was -.35 (95\% CI [-.39, -.31], $r_{\mathrm{effect}}=.74, p$ $<.001)$ and explained $61 \%$ of the within-person variance in daily self-evaluation.

In Model 3 (both positive and negative affect), at the between-person level, the impact of positive affect was $.49\left(95 \%\right.$ CI $\left.[.43, .55], r_{\text {effect }}=.74, p<.001\right)$ and the impact of negative affect was $-.15\left(95 \%\right.$ CI $\left.[-.20,-.10], r_{\text {effect }}=-.40, p<.001\right)$, together explaining $89 \%$ of the betweenperson variance in daily self-evaluation. At the within-person level, the impact of positive affect was $.34\left(95 \%\right.$ CI $\left.[.30, .38], r_{\text {effect }}=.76, p<.001\right)$ and the impact of negative affect was $-.21(95 \%$ CI $\left.[-.25,-.17], r_{\text {effect }}=.59, p<.001\right)$ together explaining $73 \%$ of the within-person variance in daily self-evaluation.

Using a state/daily measure of core self-evaluation, there was substantial within-person variance, about $44 \%$. In addition, there was a substantial impact of affect for the state selfevaluation measure $\left(R^{2}=.73\right)$.

Authenticity. In Model 0 (no predictors), the variance estimates for daily authenticity were 0.27 at the between-person level and 0.16 at the within-person level (see Table 4). The 


\section{STATE AFFECT AND EUDAIMONIA}

intraclass correlation (ICC) was .63 indicating that little more than half of the variance was between-person (63\%) vs. within-person (37\%).

In Model 1 (positive affect), the between-person impact of positive affect was .55 (95\% CI $\left.[.45, .65], r_{\text {effect }}=.62, p<.001\right)$ and explained $62 \%$ of the between-person variance. At the within-person level, the impact of positive affect was .41 (95\% CI $[.36, .47], r_{\text {effect }}=.72, p$ $<.001)$ and explained $56 \%$ of the within-person variance in daily authenticity.

In Model 2 (negative affect), the between-person impact of negative affect was -.33 (95\% CI $\left.[-.43,-.24], r_{\text {effect }}=-.43, p<.001\right)$ and explained $32 \%$ of the between-person variance. At the within-person level, the impact of negative affect was -.27 (95\% CI [-.32, -.22], $r_{\text {effect }}=-.60, p$ $<.001)$ and explained $40 \%$ of the within-person variance in daily authenticity.

In Model 3 (both positive and negative affect), at the between-person level, the impact of positive affect was $.52\left(95 \%\right.$ CI $\left.[.41, .62], r_{\text {effect }}=.56, p<.001\right)$ and the impact of negative affect was $-.04\left(95 \%\right.$ CI $\left.[-.12, .04], r_{\text {effect }}=-.07, p=.30\right)$, together explaining $62 \%$ of the betweenperson variance in daily authenticity. At the within-person level, the impact of positive affect was $.34\left(95 \%\right.$ CI $\left.[.29, .39], r_{\text {effect }}=.68, p<.001\right)$ and the impact of negative affect was -.13 $\left(95 \%\right.$ CI $\left.[-.16,-.10], r_{\text {effect }}=-.47, p<.001\right)$ together explaining $61 \%$ of the within-person variance in daily authenticity.

Using a state/daily measure of authenticity, there was substantial within-person variance, about $37 \%$. In addition, there was a strong impact of affect for state authenticity $\left(R^{2}=.61\right)$.

Positive Relationships. In Model 0 (no predictors), the variance estimates for daily positive relationships were 0.31 at the between-person level and 0.27 at the within-person level (see Table 5). The intraclass correlation (ICC) was .53 indicating that a little more than half of the variance was between-person (53\%) vs. within-person (47\%). 


\section{STATE AFFECT AND EUDAIMONIA}

In Model 1 (positive affect), the between-person impact of positive affect was .61 (95\% CI $\left.[.51, .70], r_{\text {effect }}=.65, p<.001\right)$ and explained $73 \%$ of the between-person variance. At the within-person level, the impact of positive affect was .44 (95\% CI $[.36, .52], r_{\text {effect }}=.59, p$ $<.001)$ and explained $58 \%$ of the within-person variance in daily positive relationships.

In Model 2 (negative affect), the between-person impact of negative affect was -.44 (95\% CI $\left.[-.53,-.35], r_{\text {effect }}=-.58, p<.001\right)$ and explained $45 \%$ of the between-person variance. At the within-person level, the impact of negative affect was -.33 (95\% CI [-.35, -.31], $r_{\text {effect }}=-.90, p$ $<.001)$ and explained $41 \%$ of the within-person variance in daily positive relationships.

In Model 3 (both positive and negative affect), at the between-person level, the impact of positive affect was $.36\left(95 \%\right.$ CI $\left.[.23, .49], r_{\mathrm{effect}}=.36, p<.001\right)$ and the impact of negative affect was $-.26\left(95 \%\right.$ CI $\left.[-.35,-.16], r_{\text {effect }}=-.35, p<.001\right)$, together explaining $69 \%$ of the betweenperson variance in daily positive relationships. At the within-person level, the impact of positive affect was $.33\left(95 \%\right.$ CI $\left.[.11, .54], r_{\text {effect }}=.21, p=.003\right)$ and the impact of negative affect was $-.21\left(95 \%\right.$ CI $\left.[-.39,-.02], r_{\text {effect }}=-.15, p=.027\right)$ together explaining $62 \%$ of the within-person variance in daily positive relationships.

Using a state/daily measure of positive relationships, there was substantial within-person variance, about $47 \%$. In addition, there was a strong impact of affect for state positive relationships $\left(R^{2}=.62\right)$.

Of note, the impact of affect found for these dimensions were lower than that found for state satisfaction (100\%; Jayawickreme et al., 2017b).

\section{Discussion}

As scholars of well-being endeavor to examine patterns of momentary well-being states over time, it is important to investigate whether state-based measurement of well-being indexes 


\section{STATE AFFECT AND EUDAIMONIA}

dimensions of well-being that are separable from current affect. This investigation is especially important in view of previous within-person work suggesting that state affect accounts for $100 \%$ of the within-person variance in state life satisfaction, and that individuals may rely on current affect in making short-term or "in-the-moment" appraisals of their current life circumstances (Jayawickreme et al., 2017a). The present results similarly indicated a substantial within-person relation between affect and all key dimensions of eudemonic well-being, with positive affect exhibiting a stronger relation to EWB than negative affect. However, variance in EWB dimensions explained by current affect ranged from $60 \%$ (meaning) to $73 \%$ (evaluation), suggesting that state assessments of EWB (meaning, core self-evaluations, authenticity and gratitude) do provide unique information over and above current affect. Given the current controversy over the extent to which SWB and EWB well-being are empirically distinguishable (e.g. Disabato et al., 2016; Kashdan et al., 2008), our results suggest an intermediate position. Although positive affect is in fact associated with state eudaimonia across multiple dimensions, the relationship does not appear so strong as to render these constructs interchangeable (unlike in the instance of state satisfaction).

One interpretation of these results is that the level of positive affect one feels may in fact be an appropriate source of relevant information, a phenomenon that is consistent with past results linking state positive affect with state meaning (King et al., 2006). However, people likely rely on other sources of information as well, and future research should identify these sources. For example, recent research has found that a sense of mattering (i.e., feeling that one's actions make a difference in the world and that life is worth living) was a significant precursor to trait assessments of meaning (Costin \& Vignoles, 2019). Examining the relationship between state assessments of mattering and state meaning would be an interesting question for future research. 


\section{STATE AFFECT AND EUDAIMONIA}

One possibility is that progress towards meaningful or self-transcendent goals may predict increased state meaning (Yeager et al., 2014). It is further possible that perceived proximity to close others is a situational contingency that predicts state assessments of positive relationships (Fleeson, 2007). Future research should examine specific situational contingencies associated with state changes in EWB.

We should note a number of limitations. For one, we defined state well-being in this study as attained well-being during the current day (following Jayawickreme et al., 2017b). However, substantial variability exists in range of the duration of what is considered a 'momentary' assessment in the psychological literature. As noted in Jayawickreme et al. (2017b, p. 30), King et al.'s (2006), 'momentary' assessments of PWB assessed participants' reflections over the past two days. Blackie and colleagues (2017), on the other hand, assessed state EWB five times per day. Modifying the frame of state assessments of well-being may vary the degree of impact by affect. It is conceivable that affect and dimensions of EWB exhibit lower or greater within-person association within shorter increments of time. Future research should examine the question of the ideal time frame for assessing state EWB and take into account the possibility that momentary assessments of EWB may not exhibit the same variability as momentary assessments of SWB (see Blackie et al., 2017 for data on the variability of momentary assessments of EWB).

Second, our results were based on an online sample collected on Amazon.com's Mechanical Turk platform and might not generalize to other samples (although see Buhrmester et al., 2011). Third, the data was collected at a single point each day, as opposed to random momentary assessments throughout the day. Thus, despite the benefit of the within-person approach outlined in this paper, the retrospective nature of the daily reports may render them 


\section{STATE AFFECT AND EUDAIMONIA}

biased in some manner. However, given that our focus was on well-being as opposed to specific life events, end-of-day reports may in fact be a more optimal strategy for individuals to evaluate their quality of life, and momentary assessments may not the ideal strategy for assessment state EWB (see above). Fourth, our data were observational. We assumed (and our model predicts) that changes in affect cause changes in EWB. However, we note that our observed effects may be inflated (and possibly even completely explained) by unobserved third-variable confounds. An inherent tradeoff unfortunately exists between internal and external validity, as isolating the impact of affect on satisfaction independent of the affect manipulation would be difficult, even if affect were randomly manipulated. Similar to our past work, we therefore focused on maximizing ecological validity, given the nature of our research question (Jayawickreme et al., 2017a; see also Jayawickreme et al., 2017b, p. 30). Fifth, we did not preregister this study. These data were collected in 2014, before preregistering became more prevalent in psychological research.

In conclusion, the present study utilized multi-level structural equation modeling (MLSEM) with affect as a time-varying covariate to examine the within-person relationship between current affect and state EWB. We found that the impact of affect on EWB was less consequential than for state satisfaction observed in prior research, and that the impact of positive affect on these dimensions was stronger than the impact of negative affect. This implies that while state affect and EWB are highly related, they are not interchangeable. Further research should examine other predictors of the eudaimonia that people experience in their daily lives. 


\section{STATE AFFECT AND EUDAIMONIA}

\section{Compliance with Ethical Standards}

Ethical approval: All procedures performed in studies involving human participants were in accordance with the ethical standards of the institutional research committee and with the American Psychological Association's ethical standards. The study was reviewed and approved by the Wake Forest IRB prior to data collection (IRB \# IRB00021398). No study involved research on animals.

Conflict of interest: The authors have no known conflicts of interest to disclose.

Availability of data and materials: All data and materials are available from the first author upon request.

Code availability: All code utilized in the analyses are available from the first author upon request.

Funding: This study was funded by a grant from the John Templeton Foundation (grant ID: 24322).

Informed consent: Informed consent was obtained from all individual participants included in the study.

Authors' contributions: EJ, ET and LB conceived the study; EJ, LB and BW developed materials and collected data; ET ran the analyses; EJ and ET drafted the paper; all authors provided feedback and edits on the final document 


\section{STATE AFFECT AND EUDAIMONIA}

\section{References}

Baumeister, R. F. (1991). Meanings of life. Guilford Press.

Baumert, A., Schmitt, M., Perugini, M., Johnson, W., Blum, G., Borkenau, P., Costantini, G., Denissen, J., Fleeson, W., Grafton, B., Jayawickreme, E., Kurzius, E., MacLeod, C., Miller, L., Read, L., Read, S.J., Robinson, M.D., Roberts, B., Wood, D., \& Wrzus, C. (2017). Integrating personality structure, personality process, and personality development. European Journal of Personality, 31, 503-528.

Blackie, L. E. R., Jayawickreme, E., Tsukayama, E., Forgeard, M. J., Roepke, A. M., \& Fleeson, W. (2017). Post-traumatic growth as positive personality change: Developing a measure to assess within-person variability. Journal of Research in Personality, 69, 22-32.

Bono, J. E., \& Judge, T. A. (2003). Core self-evaluations: A review of the trait and its role in job satisfaction and job performance. European Journal of personality, 17(S1), S5-S18. 


\section{STATE AFFECT AND EUDAIMONIA}

Brose, A., Schmiedek, F., Gerstorf, D., \& Voelkle, M. C. (2020). The measurement of withinperson affect variation. Emotion, 20(4), 677-699.

Buhrmester, M., Kwang, T., \& Gosling, S. D. (2011). Amazon's Mechanical Turk: A new source of inexpensive, yet high-quality, data?. Perspectives on psychological science, 6(1), 3-5.

Costin, V., \& Vignoles, V. L. (2019, January 7). Meaning Is About Mattering: Evaluating Coherence, Purpose, and Existential Mattering as Precursors of Meaning in Life Judgments. Journal of Personality and Social Psychology. Advance online publication. http://dx.doi.org/10.1037/pspp0000225

Dahill-Brown, S.E. \& Jayawickreme, E. (2016). What constitutes indices of well-being among college students? In Harward, D. W. (Ed.). Well-being and Higher Education: A Strategy for Change and the Realization of Education's Greater Purposes (pp. 123-134). Bringing Theory to Practice.

Diener, E. (1984). Subjective well-being. Psychological bulletin, 95(3), 542-575.

Diener, E., Fujita, F., Tay, L., \& Biswas-Diener, R. (2012). Purpose, mood, and pleasure in prediction satisfaction judgments. Social Indicators Research, 105, 333-341.

Disabato, D. J., Goodman, F. R., Kashdan, T. B., Short, J. L., \& Jarden, A. (2016). Different types of well-being? A cross-cultural examination of hedonic and eudaimonic well-being. Psychological assessment, 28(5), 471-482.

Duckworth, A. L., Tsukayama, E., \& May, H. (2010). Establishing causality using longitudinal hierarchical linear modeling: An illustration predicting achievement from self-control. Social Psychological and Personality Science, 1, 311-317. 


\section{STATE AFFECT AND EUDAIMONIA}

Eid, M., \& Diener, E. (2004). Global judgments of subjective well-being: Situational variability and long-term stability. Social Indicators Research, 65(3), 245-277.

Finnigan, K. M., \& Vazire, S. (2017). Personality Research is Going to Get Harder. European Journal of Personality, 31, 542-543.

Fleeson, W. (2007). Situation-based contingencies underlying trait-content manifestation in behavior. Journal of Personality, 75(4), 825-862.

Geldhof, G. J., Preacher, K. J., \& Zyphur, M. J. (2014). Reliability estimation in a multilevel confirmatory factor analysis framework. Psychological Methods, 19, 72-91.

Heppner, W. L., Kernis, M. H., Nezlek, J. B., Foster, J., Lakey, C. E., \& Goldman, B. M. (2008). Within-person relationships among daily self-esteem, need satisfaction, and authenticity. Psychological Science, 19(11), 1140-1145.

Hicks, J. A., \& King, L. A. (2007). Meaning in life and seeing the big picture: Positive affect and global focus. Cognition and Emotion, 21(7), 1577-1584.

Hudson, N. W., Lucas, R. E., \& Donnellan, M. B. (2017). Day-to-day affect is surprisingly stable: a 2-year longitudinal study of well-being. Social psychological and personality science, $8(1), 45-54$.

Jayawickreme, E., \& Dahill-Brown, S. E. (2016). Developing Well-Being and Capabilities as a Goal of Higher Education: A Thought-Piece on Educating the Whole Student. In Handbook of Eudaimonic Well-Being (pp. 473-484). Springer, Cham.

Jayawickreme, E., Forgeard, M. J. C., \& Seligman, M. E. P. (2012). The engine of well-being. Review of General Psychology, 16(4), 327-342. 


\section{STATE AFFECT AND EUDAIMONIA}

Jayawickreme, E., Tsukayama, E., \& Kashdan, T. B. (2017a). Examining the effect of affect on life satisfaction judgments: A within-person perspective. Journal of Research in Personality, 68, 32-37.

Jayawickreme, E., Tsukayama, E., \& Kashdan, T. B. (2017b). Examining the within-person effect of affect on daily satisfaction. Journal of Research in Personality, 71, 27-32.

Judge, T. A., Erez, A., Bono, J. E., \& Thoresen, C. J. (2002). Are measures of self-esteem, neuroticism, locus of control, and generalized self-efficacy indicators of a common core construct?. Journal of personality and social psychology, 83(3), 693-710.

Kandler, C. (2017). Personality Traits and States: Vague Dimensional Differentiation or Genuine Integration. European Journal of Personality, 31, 549-550.

Kashdan, T. B., Biswas-Diener, R., \& King, L. A. (2008). Reconsidering happiness: The costs of distinguishing between hedonics and eudaimonia. The Journal of Positive Psychology, 3(4), 219-233.

Kashdan, T. B., \& Steger, M. F. (2007). Curiosity and pathways to well-being and meaning in life: Traits, states, and everyday behaviors. Motivation and Emotion, 31(3), 159-173.

King, L. A., Hicks, J. A., Krull, J. L., \& Del Gaiso, A. K. (2006). Positive affect and the experience of meaning in life. Journal of Personality and Social Psychology, 90(1), 179196.

Kuppens, P., Realo, A., \& Diener, E. (2008). The role of positive and negative emotions in life satisfaction judgment across nations. Journal of Personality and Social psychology, $95(1), 66-75$. 


\section{STATE AFFECT AND EUDAIMONIA}

Lenton, A. P., Slabu, L., Sedikides, C., \& Power, K. (2013). I feel good, therefore I am real: Testing the causal influence of mood on state authenticity. Cognition \& emotion, 27(7), 1202-1224.

Little, T. D., Slegers, D. W., \& Card, N. A. (2006). A non-arbitrary method of identifying and scaling latent variables in SEM and MACS models. Structural Equation Modeling, 13(1), 59-72.

Luhmann, M., Hawkley, L. C., Eid, M., \& Cacioppo, J. T. (2012). Time frames and the distinction between affective and cognitive well-being. Journal of research in personality, 46(4), 431-441.

Molenaar, P. C., \& Campbell, C. G. (2009). The new person-specific paradigm in psychology. Current Directions in Psychological Science, 18(2), 112-117.

Reis, H. T., Sheldon, K. M., Gable, S. L., Roscoe, J., \& Ryan, R. M. (2000). Daily well-being: The role of autonomy, competence, and relatedness. Personality and social psychology bulletin, 26(4), 419-435.

Rosenthal, R., \& Rosnow, R. L. (1991). Essentials of behavioral research: Methods and data analysis. McGraw-Hill Humanities Social.

Ryan, R. M., \& Deci, E. L. (2001). On happiness and human potentials: A review of research on hedonic and eudaimonic well-being. Annual review of psychology, 52(1), 141-166.

Ryff, C. D. (1989). Happiness is everything, or is it? Explorations on the meaning of psychological well-being. Journal of personality and social psychology, 57(6), 10691081. 


\section{STATE AFFECT AND EUDAIMONIA}

Ryff, C. D., \& Keyes, C. L. M. (1995). The structure of psychological well-being revisited. Journal of personality and social psychology, 69(4), 719-727.

Sedikides, C., Slabu, L., Lenton, A., \& Thomaes, S. (2017). State authenticity. Current Directions in Psychological Science, 26(6), 521-525.

Sheldon, K. M., Ryan, R., \& Reis, H. T. (1996). What makes for a good day? Competence and autonomy in the day and in the person. Personality and social psychology bulletin, 22(12), 1270-1279.

Sheldon, K. M., Elliot, A. J., Kim, Y., \& Kasser, T. (2001). What is satisfying about satisfying events? Testing 10 candidate psychological needs. Journal of personality and social psychology, 80(2), 325-339.

Sheldon, K. M., \& Kasser, T. (2001). Getting older, getting better? Personal strivings and psychological maturity across the life span. Developmental psychology, 37(4), 491-501.

Steger, M. F., Frazier, P., Oishi, S., \& Kaler, M. (2006). The Meaning in Life Questionnaire: Assessing the presence of and search for meaning in life. Journal of Counseling Psychology, 53, 80-93.

Suh, E., Diener, E., Oishi, S., \& Triandis, H. C. (1998). The shifting basis of life satisfaction judgments across cultures: Emotions versus norms. Journal of Personality and Social Psychology, 74(2), 482-493.

Thomaes, S., Sedikides, C., van den Bos, N., Hutteman, R., \& Reijntjes, A. (2017). Happy to be “me?” Authenticity, psychological need satisfaction, and subjective well-being in adolescence. Child development, 88(4), 1045-1056. 


\section{STATE AFFECT AND EUDAIMONIA}

Waterman, A. S. (1993). Two conceptions of happiness: Contrasts of personal expressiveness (eudaimonia) and hedonic enjoyment. Journal of personality and social psychology, 64(4), 678-691.

Waterman, A. S. (2008). Reconsidering happiness: A eudaimonist's perspective. The Journal of Positive Psychology, 3(4), 234-252.

Waterman, A. S. (2013). The humanistic psychology-positive psychology divide: Contrasts in philosophical foundations. American Psychologist, 68(3), 124-133.

Widaman, K. F., Ferrer, E., and Conger, R. D. (2010). Factorial invariance within longitudinal structural equation models: Measuring the same construct across time. Child Development Perspectives 4, 10-18.

Yeager, D. S., Henderson, M. D., Paunesku, D., Walton, G. M., D'Mello, S., Spitzer, B. J., \& Duckworth, A. L. (2014). Boring but important: A self-transcendent purpose for learning fosters academic self-regulation. Journal of personality and social psychology, 107(4), 559. 


\section{STATE AFFECT AND EUDAIMONIA}

\section{Table 1}

Items Utilized

\section{Meaning}

How meaningful did you feel your life was today?

I did something today that made my life feel meaningful

How much did you feel that your life had purpose today?

I felt a sense of clarity about my life's purpose today

\section{Core self-evaluation}

I felt confident about achieving my goals today

I felt like my efforts were successful today

I failed at something today, and I felt inadequate

I completed my tasks successfully today

I did not feel in control of my routine today

I felt satisfied with myself today

I had doubts about my competence today

I felt that I was in control of my life today

I successfully met my goals today

I felt capable of coping with most of my problems today

\section{Authenticity}


STATE AFFECT AND EUDAIMONIA

Today I felt that I wore a number of social masks

Today I felt that throughout the day I was in touch with my true self

Today I felt that my choices expressed my true self

\section{Positive Relationships}

I had a meaningful conversation with a family member or friend today

I felt distant from the people around me today

\section{Current affect}

Today, I felt sad

Today, I felt happy 


\section{STATE AFFECT AND EUDAIMONIA}

Table 2

Multilevel Structural Equation Model of Affect Predicting Meaning

\begin{tabular}{|c|c|c|c|c|}
\hline & Model 0 & Model 1 & Model 2 & Model 3 \\
\hline \multicolumn{5}{|l|}{ Between-Individual Effects } \\
\hline Positive Affect ${ }^{\mathrm{a}}$ & & $.82(.04)$ & & $.80(.06)$ \\
\hline Negative Affect ${ }^{a}$ & & & $-.48(.05)$ & $-.03(.05)$ \\
\hline \multicolumn{5}{|l|}{ Within-Individual Effects } \\
\hline Positive Affect ${ }^{\mathrm{b}}$ & & $.53(.02)$ & & $.46(.02)$ \\
\hline Negative Affect ${ }^{b}$ & & & $-.31(.02)$ & $-.11(.02)$ \\
\hline Between-Individual Variance & 0.57 & 0.20 & 0.39 & 0.20 \\
\hline Within-Individual Variance & 0.26 & 0.11 & 0.17 & 0.11 \\
\hline$R^{2}$ Between & & 0.66 & 0.32 & 0.66 \\
\hline$R^{2}$ Within & & 0.57 & 0.35 & 0.60 \\
\hline
\end{tabular}

Note. Standard errors are in parentheses. ICC $=.69$. 


\section{STATE AFFECT AND EUDAIMONIA}

Table 3

Multilevel Structural Equation Model of Affect Predicting Self-Evaluations

\begin{tabular}{|c|c|c|c|c|}
\hline & Model 0 & Model 1 & Model 2 & Model 3 \\
\hline \multicolumn{5}{|l|}{ Between-Individual Effects } \\
\hline Positive Affect ${ }^{\mathrm{a}}$ & & $.61(.03)$ & & $.49(.03)$ \\
\hline Negative Affect ${ }^{\mathrm{a}}$ & & & $-.42(.03)$ & $-.15(.02)$ \\
\hline \multicolumn{5}{|l|}{ Within-Individual Effects } \\
\hline Positive Affect ${ }^{b}$ & & $.45(.02)$ & & $.34(.02)$ \\
\hline Negative Affect ${ }^{\mathrm{b}}$ & & & $-.35(.02)$ & $-.21(.02)$ \\
\hline Between-Individual Variance & 0.37 & 0.05 & 0.12 & 0.04 \\
\hline Within-Individual Variance & 0.30 & 0.10 & 0.12 & 0.08 \\
\hline$R_{\text {Between }}^{2}$ & & 0.86 & 0.69 & 0.89 \\
\hline$R^{2}$ Within & & 0.66 & 0.61 & 0.73 \\
\hline
\end{tabular}

Note. Standard errors are in parentheses. ICC $=.56$. 


\section{STATE AFFECT AND EUDAIMONIA}

Table 4

Multilevel Structural Equation Model of Affect Predicting Authenticity

\begin{tabular}{|c|c|c|c|c|}
\hline & Model 0 & Model 1 & Model 2 & Model 3 \\
\hline \multicolumn{5}{|l|}{ Between-Individual Effects } \\
\hline Positive Affect ${ }^{\mathrm{a}}$ & & $55(.05)$ & & $.52(.05)$ \\
\hline Negative Affect ${ }^{\mathrm{a}}$ & & & $-.33(.05)$ & $-.04(.04)$ \\
\hline \multicolumn{5}{|l|}{ Within-Individual Effects } \\
\hline Positive Affect ${ }^{b}$ & & $.41(.03)$ & & $.34(.03)$ \\
\hline Negative Affect ${ }^{\mathrm{b}}$ & & & $-.27(.03)$ & $-.13(.02)$ \\
\hline Between-Individual Variance & 0.27 & 0.10 & 0.19 & 0.10 \\
\hline Within-Individual Variance & 0.16 & 0.07 & 0.10 & 0.06 \\
\hline$R^{2}$ Between & & 0.62 & 0.32 & 0.62 \\
\hline$R^{2}$ Within & & 0.56 & 0.40 & 0.61 \\
\hline
\end{tabular}

Note. Standard errors are in parentheses. ICC $=.63$. 


\section{STATE AFFECT AND EUDAIMONIA}

Table 5

Multilevel Structural Equation Model of Affect Predicting Positive Relationships

\begin{tabular}{lcccc}
\hline & Model 0 & Model 1 & Model 2 & Model 3 \\
\hline $\begin{array}{l}\text { Between-Individual Effects } \\
\quad \text { Positive Affect }\end{array}$ & & & & \\
$\quad \begin{array}{l}\text { Negative Affect } \\
\text { Within-Individual Effects } \\
\quad \text { Positive Affect }\end{array}$ & & $.61(.05)$ & & $.36(.07)$ \\
$\quad$ Negative Affect & & & $-.44(.04)$ & $-.26(.05)$ \\
& & & & \\
Between-Individual Variance & 0.31 & 0.08 & 0.17 & $.33(.11)$ \\
Within-Individual Variance & 0.27 & 0.11 & 0.16 & 0.10 \\
\hline$R_{\text {Between }}^{2}$ & & 0.73 & 0.45 & 0.10 \\
$R^{2}{ }_{\text {Within }}$ & & 0.58 & 0.41 & 0.69 \\
\hline
\end{tabular}

Note. Standard errors are in parentheses. ICC $=.53$. 